\title{
Focal Lipodystrophy
}

National Cancer Institute

\section{Source}

National Cancer Institute. Focal Lipodystrophy. NCI Thesaurus. Code C131814.

Loss of subcutaneous fat confined to small area(s) of the body. 